\title{
Quais são as técnicas comportamentalistas que os docentes consideram mais eficazes nas crianças com Perturbação de Hiperatividade com Défice de Atenção?
}

\author{
Eduardo Chaves Cruz* \\ Cecilia Mendes Espinho Brito**
}

\section{Resumo}

A Perturbação de Hiperatividade com Défice de Atenção (PHDA) é uma perturbação neurocomportamental que se caracteriza por padrōes persistentes e níveis desadequados de desatenção e/ou hiperatividade-impulsividade. É o distúrbio mais frequente em idade escolar, pelo que se torna pertinente que o professor saiba intervir adequadamente, recorrendo a estratégias educativas e comportamentais apropriadas, tendo em vista o sucesso académico e a integração social. Atualmente, a PHDA é provavelmente a perturbação da infância mais estudada e com a qual os docentes do $1 .^{\circ}$ Ciclo mais se debatem no seu quotidiano. No presente estudo, com o objetivo de identificar as técnicas comportamentalistas, baseadas no reforço positivo e na punição que os docentes consideram mais eficazes para modificar o comportamento das crianças com Perturbação de Hiperatividade com Défice de Atenção e qual é a frequência com que recorrem à sua utilização, elaborou-se e aplicou-se um questionário a uma amostra de duzentos e cinquenta docentes. Os resultados obtidos evidenciam que os docentes utilizam com maior frequência o Contrato de Contingências e o Custo da resposta, atribuindo-lhes uma eficácia superior comparativamente com o Time-Out e o Programa de economia de fichas.

Palavras-chave: Perturbação de Hiperatividade com Défice de Atenção; Técnicas comportamentalistas; Comportamento.

* Professor doutor da Universidade de Trás-Os-Montes e Alto Douro, Vila Real, Portugal.

** Mestre em Educação Especial - Domínio Cognitivo e Motor pela Universidade de Trás-Os-Montes e Alto Douro, Vila Real, Portugal. 


\section{Which are the behavioral techniques that teachers consider more efficient in children with Attention Deficit Hyperactivity Disorder?}

\section{Abstract}

The Attention Deficit Hyperactivity Disorder (ADHD) is a neurobehavioral disorder characterized by persistent patterns and inadequate levels of inattention and/or hyperactivity-impulsivity. It is the most frequent disorder of school age, and, therefore, it is relevant that teachers know how to intervene appropriately, using educational and behavioral strategies in view of academic success and social integration. Currently, ADHD is probably the most studied disorder of childhood and with which 1st cycle teachers most are faced in their daily lives. In this study, in order to identify the behavioral techniques based in positive reinforcement and punition that teachers consider more efficient to change the behavior of children with ADHD and what's the frequency of their use, a questionnaire was developed and applied to a sample of two hundred and fifty teachers. The results show, that teachers use more frequently the Contingency Contract and Response Cost and attribute to these techniques more efficacy than those related with Time Out and Token Economy program.

Keywords: Attention Deficit Hyperactivity Disorder; Behavioral techniques; Behavior.

\section{Introdução}

A Perturbação de Hiperatividade com Défice de Atenção (PHDA) afigura-se como uma perturbação do sistema nervoso central que apresenta um quadro sintomático diversificado e interfere significativamente na vida social, familiar e académica das crianças e, consequentemente, no seu normal desenvolvimento.

De acordo com a definiçáo proposta pela Associação Americana de Psiquiatria (AAP), no Manual de Diagnóstico e Estatística das Perturbações Mentais, a PHDA é classificada como uma desordem disruptiva do comportamento e do défice de atenção, incluindo-se na classificação das perturbaçôes que surgem na primeira e segunda infâncias ou na adolescência. É uma perturbação neurocomportamental que se caracteriza por padrôes persistentes e níveis desadequados de desatenção e/ou hiperatividade-impulsividade, sendo o distúrbio mais frequente em idade escolar.

Esta síndrome surge na infância e caracteriza-se por dificuldades significativas em manter a atenção, a impulsividade e a hiperatividade. Regra geral, esta perturbação é detetada quando a criança inicia as atividades de aprendizagem na escola, devido ao grau de exigência das tarefas propostas ao nível da atenção/concentração, quer pelo maior tempo de realização das mesmas. No entanto, também se pode manifestar em idades mais precoces, nomeadamente ao nível do pré-escolar.

A desatenção, a hiperatividade e a impulsividade são as características nucleares da PHDA, manifestando-se com uma intensidade mais acentuada do que em in- 
divíduos com um nível semelhante de desenvolvimento (BOAVIDA; CORDINHÁ, 2008). Estes autores referem ainda que a desatenção é um sintoma constante nesta perturbaçáo, apesar de nem sempre ser evidente. Esta perspetiva é corroborada por Silva (2009, p. 19) que refere que "uma pessoa com comportamento PHDA pode ou não apresentar hiperatividade física, mas jamais deixará de apresentar forte tendência à dispersão".

A PHDA assume-se como uma problemática bastante complexa e de acordo com Sena e Neto (2007) atinge cerca de 3\% a 7\% dos alunos ou seja duas em cada trinta crianças. Deste modo, torna-se imperativo que os docentes saibam lidar com os problemas significativos de desatenção, hiperatividade e impulsividade, de forma a evitar que estes perturbem não só o ambiente na sala de aula, como também o seu rendimento escolar e o dos colegas.

Dependendo do subtipo de Perturbação de Hiperatividade com Défice de Atenção e das comorbidades associadas devemos ter em consideração que os sintomas e características da PHDA variam de indivíduo para indivíduo. Em ambiente escolar, estas crianças distraem-se facilmente, são desorganizadas, têm um rendimento escolar oscilante e é-lhes muito difícil concentrarem-se o tempo suficiente para completar tarefas diárias rotineiras e comuns. Náo são capazes de estar sentadas durante muito tempo, correm, interferem e implicam com os outros. Mesmo quando sentadas, mexem os pés ou as mãos, mudam de posição e fazem ruídos com os objetos que têm nas mãos. Têm uma enorme dificuldade em inibir ou parar uma resposta, comentário ou comportamento. Falam, comentam, respondem e reagem sem pensar primeiro nas consequências, podendo tornar-se inconvenientes e desagradáveis. Tal como afirma Lopes (2004), estas crianças são descritas pelos professores como irrequietas e barulhentas e incapazes de permanecer nos seus lugares, fatores que contribuem para a ocorrência de disfuncionalidades nas dinâmicas escolares e nas práticas educativas.

No que diz respeito ao tratamento da PHDA, DuPaul e Stoner (2007) afirmam que, apesar de não existir nenhum que cure esta perturbação, há inúmeras formas de intervençáo que efetivamente podem ajudar a minimizar os transtornos que esta provoca a diversos níveis. Assim, os vários tipos de intervenção existentes estão direcionados para reduzir os sintomas nucleares da PHDA (hiperatividade, impulsividade e défice de atenção) ou para amenizar os demais problemas associados à perturbação (SHELTON; BARKLEY, 1995; GOLDSTEIN, 1998 apud JÚLIO, 2009). De um modo geral, sem uma intervenção adequada, atempada e pluridisciplinar as crianças com PHDA podem apresentar ao longo da sua vida vários problemas associados, nomeadamente: dificuldades de aprendizagem (insucesso escolar), problemas emocionais, como depressão e/ou sentimentos de desconfiança/insegurança e baixa autoestima, problemas de comportamento e de personalidade e dificuldades nas relaçôes familiares e sociais.

Sendo o comportamento disruptivo umas das principais características das crianças com PHDA, quando falamos em intervenção em contexto de sala de aula referimo-nos inevitavelmente à implementação de estratégias que incidam na modificação desses comportamentos. Inúmeras abordagens relacionadas com a modificação 
da conduta das crianças com PHDA centram-se em estratégias do condicionamento operante pois partem do princípio que o nosso comportamento depende das consequências que o acompanham. Como tal, pretendem aumentar os comportamentos desejáveis e, simultaneamente diminuir os comportamentos indesejáveis reforçando ou punindo as consequências. Deste modo, tal como certifica Chaves (2008), as consequências positivas tendem a produzir novos comportamentos e a manter os adequados enquanto consequências negativas provocam uma diminuição de comportamentos disruptivos ou levam à sua extinção. Nas últimas décadas, as técnicas de gestão comportamental têm sido amplamente estudadas (HORNER; et al., 2000) uma vez que quase todos os educadores utilizam algumas delas na sala de aula com crianças com PHDA e não só (REIBER; MCLAUGHLIN, 2004).

É neste âmbito que surge o presente trabalho de investigação cujo objetivo primordial é identificar as técnicas comportamentalistas, baseadas no reforço positivo e na punição, que os docentes consideram mais eficazes para modificar o comportamento das crianças com Perturbação de Hiperatividade com Défice de Atenção e, simultaneamente apurar qual a frequência com que recorrem à sua utilização.

A investigação foi orientada no sentido de dar resposta ao seguinte problema de pesquisa: "Quais são as técnicas comportamentalistas que os docentes consideram mais eficazes para modificar o comportamento das crianças com Perturbação de Hiperatividade com Défice de Atenção e qual a frequência com que recorrem à sua utilização?”

\section{Método}

\section{Característica dos participantes}

No presente estudo, participaram duzentos e cinquenta docentes, do $1 .^{\circ}$ Ciclo do Ensino Básico, selecionados aleatoriamente da população em estudo. A caracterização dos participantes do estudo foi realizada tendo por base o género, a idade, as habilitaçóes académicas e o tempo de serviço.

No que concerne ao género da amostra, dos duzentos e cinquenta docentes inquiridos, $86,4 \%$ são do sexo feminino e apenas $13,6 \%$ são do sexo masculino.

Relativamente à idade, $57,6 \%$ dos inquiridos têm idades compreendidas entre os 30 e os 40 anos, seguindo-se a classe dos 41 aos 50 anos com 24,4\%. Apenas 2,4\% dos docentes possuem menos de trinta anos e 15,6 \% têm mais de 50 anos.

No que diz respeito às habilitaçôes académicas, 49,6\% dos docentes têm Licenciatura, 13,2\% possuem uma Pós-Graduação/Especialização, 34\% têm Mestrado e somente $0,4 \%$ fizeram Doutoramento.

No que respeita à experiência profissional, $38 \%$ dos docentes têm entre $11 \mathrm{e}$ 20 anos de tempo de serviço, $27,6 \%$ têm mais de 20 anos, $11,6 \%$ possuem menos de 5 anos e $22,8 \%$ têm entre 5 e 10 anos de docência. 


\section{Instrumentos}

No presente estudo, optou-se por utilizar como instrumento de recolha de dados um questionário constituído exclusivamente por questôes fechadas, agrupadas em dois grupos de acordo com o conhecimento que se pretendia obter.

Para determinar a consistência interna do questionário realizou-se o teste Alfa de Cronbach. Esta análise permitiu determinar que o questionário apresenta um nível de confiabilidade aceitável na medida em que $\alpha=0,716$.

O questionário foi elaborado no Google Docs, um pacote de aplicativos do Google que permite criar e editar documentos online, e divulgado a docentes do $1^{\circ}$ Ciclo do Ensino Básico via e-mail, através do link: https://docs.google.com/forms/ d/1v-3GEAToeuAxodq5HphKeMYHDJFJ2sTL7wUT7_hEiyQ/viewform.

\section{Procedimentos}

Fase1 - Definidos os objetivos do estudo, a questão de investigação e após uma revisão da literatura procedeu-se à elaboração do questionário no Google Docs.

Fase 2 - O questionário foi distribuído e aplicado via e-mail a duzentos e cinquenta docentes do $1^{\circ}$ Ciclo do Ensino Básico. Os docentes inquiridos foram devidamente informados acerca dos objetivos e do tipo de estudo que se pretendia realizar, bem como que as informaçôes recolhidas se destinavam apenas a ser utilizadas para efeitos de estudo, salvaguardando a confidencialidade das respostas.

Fase 3 - Recolha de dados do questionário.

Fase 4 - Análise estatística dos resultados obtidos recorrendo ao programa SPSS (versão20.0) e ao Microsoft Excel.

\section{Análise dos resultados}

Por forma a responder à questão de investigação formulada indagamos, em primeiro lugar, os docentes acerca do grau de eficácia que atribuem às diferentes formas de intervenção junto das crianças com PHDA, para estabelecer uma comparação com a eficácia atribuída à intervenção comportamentalista. Posteriormente, averiguou-se qual a eficácia que os docentes atribuem às diferentes técnicas comportamentalistas, baseadas no reforço positivo e na punição, na modificação dos comportamentos desadaptados das crianças com PHDA.

Deste modo, no que concerne às diferentes formas de intervenção com as crianças com PHDA, como podemos observar na tabela 1, apuramos que a maioria dos docentes é unanime ao afirmar que todas as intervençóes são eficazes na maioria das situaçóes e que náo há nenhuma que seja totalmente eficaz. 
Tabela 1 - Grau de eficácia que os docentes atribuem às diferentes formas de intervenção com a criança com PHDA

\begin{tabular}{|c|c|c|c|c|c|c|}
\hline & & $\begin{array}{l}\text { Totalmente } \\
\text { ineficaz }\end{array}$ & $\begin{array}{c}\text { Ineficaz } \\
\text { na } \\
\text { maioria } \\
\text { das } \\
\text { situaçóes }\end{array}$ & $\begin{array}{c}\text { Nem } \\
\text { eficaz } \\
\text { nem } \\
\text { ineficaz }\end{array}$ & $\begin{array}{c}\text { Eficaz na } \\
\text { maioria } \\
\text { das } \\
\text { situaçóes }\end{array}$ & $\begin{array}{c}\text { Totalmente } \\
\text { eficaz }\end{array}$ \\
\hline \multirow{2}{*}{$\begin{array}{l}\text { Intervenção } \\
\text { farmacológica }\end{array}$} & $\mathrm{N}$ & 2 & 22 & 28 & 194 & 4 \\
\hline & $\%$ & $0,8 \%$ & $8,8 \%$ & $11,2 \%$ & $77,6 \%$ & $1,6 \%$ \\
\hline \multirow{2}{*}{$\begin{array}{l}\text { Intervençáo } \\
\text { psicossocial }\end{array}$} & $\mathrm{N}$ & 1 & 8 & 27 & 183 & 31 \\
\hline & $\%$ & $0,4 \%$ & $3,2 \%$ & $10,8 \%$ & $73,2 \%$ & $12,4 \%$ \\
\hline \multirow{2}{*}{$\begin{array}{l}\text { Intervençáo } \\
\text { comportamentalista }\end{array}$} & $\mathrm{N}$ & 1 & 5 & 42 & 177 & 25 \\
\hline & $\%$ & $0,4 \%$ & $2,0 \%$ & $16,8 \%$ & $70,8 \%$ & $10,0 \%$ \\
\hline \multirow{2}{*}{ Terapia familiar } & $\mathrm{N}$ & 2 & 12 & 54 & 149 & 33 \\
\hline & $\%$ & $0,8 \%$ & $4,8 \%$ & $21,6 \%$ & $59,6 \%$ & $13,2 \%$ \\
\hline \multirow{2}{*}{$\begin{array}{l}\text { Intervençáo cognitiva- } \\
\text { comportamentalista }\end{array}$} & $\mathrm{N}$ & 1 & 5 & 33 & 178 & 33 \\
\hline & $\%$ & $0,4 \%$ & $2,0 \%$ & $13,2 \%$ & $71,2 \%$ & $13,2 \%$ \\
\hline
\end{tabular}

Relativamente à intervenção comportamentalista, analisando a tabela 1, podemos apurar que 70,8\% dos docentes (177) consideram-na eficaz na maioria das situaçóes e apenas 10,0\% (25) referem que é totalmente eficaz. Em contrapartida, apenas uma parte exígua da amostra refere que este tipo de intervenção é ineficaz na maioria das situaçóes $(2,0 \%)$ ou totalmente ineficaz $(0,4 \%)$. Podemos referir ainda que $16,8 \%$ dos professores (42) náo consideram a modificaçáo de comportamento das crianças com PHDA uma forma de intervenção eficaz nem ineficaz.

Em relação à intervenção farmacológica, podemos asseverar que $77,6 \%$ docentes (194) consideram que este tipo de intervenção surte resultados eficazes na maioria das intervençóes com crianças com PHDA enquanto 1,6\% dos inquiridos (4) pensam que é totalmente eficaz. Relativamente aos docentes que discordam destes pareceres, podemos referir que estes representam uma parte pouco significativa da amostra na medida em que apenas $8,8 \%$ (22) consideram que recorrer a fármacos é ineficaz na maioria das situaçôes e 0,8 \% (2) totalmente ineficaz.

No que concerne à intervenção psicossocial, podemos afirmar que os seus resultados são reconhecidos pela maioria dos docentes, uma vez que $73,2 \%$ (183) consideram-na eficaz na maioria das situaçóes e 12,4 \% (31) totalmente eficaz. Por oposição, uma parte reduzida da amostra entende que esta intervenção não é adequada uma vez que os seus resultados são totalmente ineficazes $(0,4 \%)$ ou ineficazes na maioria das situaçóes (3,2\%). Importa ainda referir que 10,8\% dos docentes (27) não têm uma opiniáo formada acerca dos resultados deste tipo de intervenção junto das crianças com PHDA, pelo que não a consideram eficaz ou ineficaz.

Em relação à intervenção cognitiva-comportamentalista, podemos referir que os docentes reconhecem a sua eficácia na gestão dos comportamentos das crianças 
com PHDA, na medida em que $71,2 \%$ dos inquiridos (178) classificam-na como eficaz na maioria das situações e $13,2 \%$ (33) totalmente eficaz. Por oposição, uma percentagem muito escassa de professores não considera que uma intervenção cognitiva-comportamentalista promova uma mudança de comportamentos disruptivos nas crianças com PHDA, considerando-a totalmente ineficaz $(0,4 \%)$ ou ineficaz na maioria das situaçóes $(2,0 \%)$. Existe ainda uma percentagem diminuta da amostra $(13,2 \%)$ que não atribui qualquer grau de eficiência ou ineficiência a este tipo de intervenção.

No que respeita à terapia familiar, os docentes reconhecem que este tipo de intervençáa produz resultados eficazes na gestáo dos comportamentos disruptivos dos alunos com PHDA, na medida em que 59,6\% dos inquiridos (149) asseguram a sua eficiência na maioria das situaçóes e 13,2\% (33) em todas as situaçóes. Uma parte diminuta dos inquiridos pensa que esta intervenção é totalmente ineficaz $(0,8 \%)$ e 4,8\% (12) encaram-na como ineficaz na maioria das situaçôes. Por sua vez, uma percentagem algo expressiva de respondentes $(21,6 \%)$ não confere qualquer grau de eficiência ou ineficiência a uma intervenção de âmbito familiar.

$\mathrm{Na}$ medida em que a intervenção comportamentalista, no tratamento da hiperatividade, recorre a diferentes técnicas baseadas no reforço positivo e na punição, averiguou-se o grau de eficácia que os docentes atribuem a cada uma delas. Observando a tabela 2 , verificamos que, os resultados sugerem que a maioria dos docentes inquiridos considera que as diferentes técnicas comportamentalistas são eficazes na maioria das situaçôes, com exceçâoo do Time-Out.

No que respeita à estratégia Contrato de Contingências deve ser realçado que uma percentagem expressiva de docentes, 70,0\% (175), considera que esta é eficaz na maioria das situaçôes e 3,2\% (8) pensa que é totalmente eficaz. Por oposição, uma percentagem muito ténue de docentes considera que a elaboração de contratos, entre o docente e a criança com PHDA, é totalmente ineficaz $(0,4 \%)$ ou ineficaz na maioria dos casos $(8,0 \%)$. Os docentes que não têm uma opinião clara quanto à eficácia ou ineficácia da elaboração de um Contrato de Contingências representam 18,4\% da amostra (46).

No que concerne à perceção que os professores têm acerca da estratégia Custo da Resposta, analisando a tabela 2, os resultados sugerem que metade dos inquiridos $(55,2 \%)$ considera que esta é eficaz na maioria das situações e 3,2\% (8) reconhecelhe uma eficácia total. Quanto aos docentes que não consideram que esta estratégia surta resultados eficazes na intervenção das crianças com PHDA constatamos que estes representam apenas $12,4 \%$ da amostra. Deve ainda ser realçado que $29,2 \%$ dos professores não têm uma opiniáo clara acerca dos resultados que se obtêm com a utilização desta estratégia punitiva.

No que diz respeito à estratégia Programa de Economia de Fichas, os resultados parecem sugerir que a sua eficácia é reconhecida por metade dos docentes inquiridos (49,2\%), no entanto apenas 3,2\% (8) atribuem-lhe uma eficácia total. Em contrapartida, 9,2\% dos respondentes (23) consideram que a elaboração deste tipo de programas não surte os efeitos desejados pelo que consideram a sua aplicação 
totalmente ineficaz $(2,8 \%)$ ou ineficaz na maioria das situaçóes $(6,4 \%)$. Deve ser igualmente salientado que uma percentagem indicativa da amostra $(38,4 \%)$ não atribui qualquer grau de eficácia ou ineficácia a este tipo de prática educativa, pois como pudemos apurar no nosso estudo a maioria dos inquiridos afirmou nunca ter recorrido a esta estratégia ou fazê-lo raramente.

No que diz respeito ao Time-Out, deve ser realçado o elevado número de docentes que refere que esta estratégia não é eficaz nem ineficaz, na interação com crianças com PHDA, na medida em que representam 37,6\% da amostra (94). A eficiência desta estratégia punitiva apenas é reconhecida por uma percentagem não muito expressiva de docentes, sendo que 28,8\% (72) atribuem-lhe uma eficácia na maioria das situaçóes e somente 3,2\% (8) aceitam uma eficácia total. Por oposiçấo, 23,2\% dos inquiridos (58) consideram que a utilização do Time-Out é ineficaz na maioria das situaçóes e 7,2\% (18) afirmam ser totalmente ineficaz.

Tabela 2 - Grau de eficácia que os docentes atribuem às diferentes técnicas comportamentalistas na interação com crianças com PHDA.

\begin{tabular}{|c|c|c|c|c|c|c|}
\hline & & $\begin{array}{c}\text { Totalmente } \\
\text { Ineficaz }\end{array}$ & $\begin{array}{c}\text { Ineficaz } \\
\text { na } \\
\text { maioria } \\
\text { das } \\
\text { situaçóes }\end{array}$ & $\begin{array}{c}\text { Nem } \\
\text { eficaz } \\
\text { nem } \\
\text { ineficaz }\end{array}$ & $\begin{array}{c}\text { Eficaz na } \\
\text { maioria } \\
\text { das } \\
\text { situaçóes }\end{array}$ & $\begin{array}{c}\text { Totalmente } \\
\text { eficaz }\end{array}$ \\
\hline \multirow{2}{*}{$\begin{array}{l}\text { Contrato de } \\
\text { Contingências }\end{array}$} & $\mathrm{N}$ & 1 & 20 & 46 & 175 & 8 \\
\hline & $\%$ & $0,4 \%$ & $8,0 \%$ & $18,4 \%$ & $70,0 \%$ & $3,2 \%$ \\
\hline \multirow{2}{*}{$\begin{array}{l}\text { Custo da } \\
\text { Resposta }\end{array}$} & $\mathrm{N}$ & 3 & 28 & 73 & 138 & 8 \\
\hline & $\%$ & $1,2 \%$ & $11,2 \%$ & $29,2 \%$ & $55,2 \%$ & $3,2 \%$ \\
\hline \multirow{2}{*}{$\begin{array}{l}\text { Programa de } \\
\text { Economia de } \\
\text { Fichas }\end{array}$} & $\mathrm{N}$ & 7 & 16 & 96 & 123 & 8 \\
\hline & $\%$ & $2,8 \%$ & $6,4 \%$ & $38,4 \%$ & $49,2 \%$ & $3,2 \%$ \\
\hline \multirow{2}{*}{ Time-Out } & $\mathrm{N}$ & 18 & 58 & 94 & 72 & 8 \\
\hline & $\%$ & $7,2 \%$ & $23,2 \%$ & $37,6 \%$ & $28,8 \%$ & $3,2 \%$ \\
\hline
\end{tabular}

Por forma a averiguar qual a frequência com que os docentes do $1^{\circ}$ Ciclo do Ensino Básico recorrem às técnicas comportamentalistas, baseadas no reforço positivo e na punição, indagaram-se somente os 198 docentes que referiram já ter trabalhado com alunos com PHDA em contexto escolar. Relativamente às técnicas baseadas no reforço positivo, o Contrato de Contingências e o Programa de Economia de Fichas, observando a tabela 3, podemos apurar que os docentes recorrem com maior frequência ao Contrato de Contingências. No que concerne às técnicas baseadas na punição, constatamos que os docentes privilegiam o Custo da Resposta, em detrimento do Time-Out.

Analisando a frequência com que os docentes referem utilizar cada uma das diferentes técnicas comportamentalistas, para trabalhar com crianças com PHDA, podemos afirmar que a mais utilizada é o Contrato de Contingências, na medida em que $46,0 \%$ dos inquiridos (91) referem utilizá-lo muitas vezes e 7,1\% (14) indicam 
uma utilização permanente. Em oposição, $12,1 \%$ dos inquiridos (24) referem nunca ter recorrido a esta técnica e $6,1 \%$ (12) asseguram utilizá-la raramente. No que respeita à outra técnica baseada no reforço positivo, Programa de Economia de Fichas, podemos aferir que os docentes valem-se da sua utilização com pouca frequência, na medida em que $33,8 \%$ dos inquiridos (67) referem que apenas a utilizam às vezes, $20,7 \%$ (41) raramente e $25,8 \%$ (51) nunca a utilizaram.

Relativamente às técnicas baseadas na punição, continuando a análise da tabela 3, podemos afirmar que o Custo da Resposta é utilizado com maior frequência pelos docentes do que o Time-Out, na medida em que 34,3\% (68) referem recorrer a esta estratégia às vezes e $28,3 \%$ (56) utilizam-na muitas vezes. No que concerne à outra técnica punitiva, Time-Out, podemos constatar que é utilizada com pouca frequência pelos docentes uma vez que 36,4\% (72) referem nunca a ter utilizado e $23,7 \%$ (47) fazem-no raramente. Verificamos, ainda, que 23,2\% (46) dos inquiridos utilizam o Time- Out às vezes e apenas 14,6\% (29) referem utilizá-lo muitas vezes. Somente uma percentagem pouco significativa de docentes $(2 \%)$ refere que utiliza sempre esta técnica punitiva para lidar com o comportamento disruptivo das crianças com PHDA.

Tabela 3 - Frequência com que os docentes recorrem às técnicas comportamentalistas baseadas no reforço positivo e na punição para trabalhar com crianças com PHDA.

\begin{tabular}{l|l|c|c|c|c|c}
\hline \multicolumn{2}{c|}{} & Nunca & Raramente & Às vezes & Muitas vezes & Sempre \\
\hline $\begin{array}{l}\text { Contrato de } \\
\text { Contingências }\end{array}$ & $\mathrm{N}$ & 24 & 12 & 57 & 91 & 14 \\
\cline { 2 - 7 } & $\%$ & $12,1 \%$ & $6,1 \%$ & $28,8 \%$ & $46,0 \%$ & $7,1 \%$ \\
\hline $\begin{array}{l}\text { Custo da } \\
\text { Resposta }\end{array}$ & $\mathrm{N}$ & 32 & 27 & 68 & 56 & 15 \\
\cline { 2 - 7 } & $\%$ & $16,2 \%$ & $13,6 \%$ & $34,3 \%$ & $28,3 \%$ & $7,6 \%$ \\
\hline $\begin{array}{l}\text { Programa de } \\
\begin{array}{l}\text { Economia de } \\
\text { Fichas }\end{array}\end{array}$ & $\mathrm{N}$ & 51 & 41 & 67 & 34 & 5 \\
\cline { 2 - 7 } & $\%$ & $25,8 \%$ & $20,7 \%$ & $33,8 \%$ & $17,2 \%$ & $2,5 \%$ \\
\hline \multirow{2}{*}{ Time-Out } & $\mathrm{N}$ & 72 & 47 & 46 & 29 & 4 \\
\cline { 2 - 7 } & $\%$ & $36,4 \%$ & $23,7 \%$ & $23,2 \%$ & $14,6 \%$ & $2,0 \%$ \\
\hline
\end{tabular}

\section{Discussão/Conclusão}

O objetivo geral do estudo foi identificar as técnicas comportamentalistas, baseadas no reforço positivo e na punição, que os docentes consideram mais eficazes para modificar o comportamento das crianças com Perturbação de Hiperatividade com Défice de Atenção e, simultaneamente, qual a frequência com que recorrem à sua utilização. Os resultados obtidos, através das análises estatísticas efetuadas, evidenciaram que, no que concerne às diferentes formas de intervenção, os docentes são unanimes ao afirmar que todas as intervençôes são eficazes na maioria das situaçóes e que não há nenhuma que seja totalmente eficaz. Verificamos ainda que os docentes atribuem um grau de eficácia superior a 70\% a todas as formas de intervençáo, à exceção da terapia familiar, que obteve apenas 59,6\%, um valor significativamente inferior. Por outro lado, importa ainda realçar que, fazendo um somatório dos graus "eficaz 
na maioria das situaçôes" e "totalmente eficaz", verificamos que os docentes atribuem maior eficácia, na intervenção com crianças com $\mathrm{PHD}$, à intervençâo psicossocial $(85,6 \%)$, seguindo-se a cognitiva-comportamentalista $(84,4 \%)$, a comportamentalista $(80,8 \%)$, a farmacológica $(79,2 \%)$ e, por último, a terapia familiar $(72,8 \%)$. Em suma, concluímos que os docentes reconhecem eficácia às diferentes formas de intervenção, perspetiva esta que é corroborada pela literatura existente neste âmbito, na medida em que inúmeras investigaçóes apontam para a necessidade de recorrer a diferentes estratégias e métodos, devido ao caráter multidimensional desta perturbação (FERNANDES, 2007; DUPAUL;STONER, 2007; ARRUDA, 2008; SAUVÉ, 2006; ABAD-MAS; et al., 2013). Estabelecendo uma comparação com o estudo de Cardoso (2013) constatamos algumas semelhanças nos resultados obtidos, na medida em que $75 \%$ dos professores inquiridos, no seu estudo, consideram a colaboração da escola com os pais como a forma de intervenção mais profícua para as crianças com PHDA e a terapia familiar surge como uma das estratégias menos reconhecida. Os resultados também estão em consonância com os obtidos nos estudos realizados por Lourenço (2009) e Roberto (2013), nos quais a intervenção (colaboração) escolar/ familiar foi considerada como a mais benéfica para a criança com PHDA, seguindo-se a introdução de estratégias educativas específicas na sala de aula. Por oposiçáo, no estudo de Santos (2012), quando questionados os docentes sobre as formas de intervenção consideradas mais benéficas para a criança com PHDA, menciona-se, em primeiro lugar, uma intervenção escolar/académica, seguida da medicação e só posteriormente surgem a colaboração pais/escola e a introdução de estratégias educativas específicas. Em suma, no que se refere à eficácia das diferentes formas de intervenção, verificamos que as investigaçóes realizadas neste âmbito reconhecem a eficiência de todas elas, no entanto a revisão da literatura evidencia que há unanimidade em afirmar que a intervenção mais eficaz é a multimodal, caracterizando-se por envolver diversas formas de intervenção e os diferentes ambientes da criança (escolar e familiar).

Relativamente ao grau de eficácia que os docentes atribuem às técnicas comportamentalistas, Time-Out, Contrato de Contingências, Programa de Economia de Fichas e Custo da Resposta, apuramos que, na generalidade, os inquiridos consideram que estas são eficazes na maioria das situaçôes, com exceção do Time-Out. No que diz respeito a esta técnica, a percentagem de docentes que a considera eficaz na maioria das situaçôes ou totalmente eficaz é reduzida, representando apenas 32\% da amostra. No entanto, também é de salientar que é reconhecida como ineficaz na maioria das situaçóes ou totalmente ineficaz por 30,4\% dos inquiridos. Fazendo uma análise mais minuciosa dos dados estatísticos obtidos, podemos constatar que é ao Contrato de Contingências que os docentes atribuem um maior grau de eficácia no trabalho com crianças com PHDA, seguindo-se o Custo da Resposta e o Programa de Economia de Fichas. Relativamente a este aspeto da nossa investigação, estabelecendo uma análise comparativa com outros estudos realizados neste âmbito, constatamos que a literatura evidencia, na generalidade, a eficácia das diferentes técnicas comportamentalistas, utilizadas de forma combinada ou isolada, no tratamento de crianças com PHDA. No entanto, não encontramos estudos onde se tenham indagado os docentes do $1 .^{\circ}$ Ciclo ou de outros graus de ensino acerca do grau de eficácia que 
atribuem a cada uma delas, denotando-se deste modo o caráter inovador do estudo. No entanto, podemos enumerar diversos estudos que comprovaram a eficácia destas técnicas em contexto escolar, na medida em que foram aplicadas, solitariamente ou juntamente, para impulsionar a alteração de comportamentos disruptivos em crianças com PHDA e/ou estimular a manutenção de comportamentos ajustados. Por exemplo, Marafão (2012) comprovou a eficácia do Programa de Economia de Fichas associado ao Custo da Resposta, assim como Zambom et al. (2006) e Simonsen et al. (2008) comprovaram a eficiência dos Programas de Economia de Fichas utilizados isoladamente; Carlson e Tamm (2000) obtiveram melhorias no rendimento escolar de crianças com PHDA através da aplicação de um programa de Custo da Resposta e Loro-López et al. (2009) e Abad-Mas et al. (2013) consideraram o Custo da Resposta e o Time-Out como estratégias de referência no tratamento de crianças hiperativas. Em suma, fica evidente que, de um modo geral, a revisão da literatura reconhece a eficácia de cada uma destas técnicas de condicionamento operante.

No que se refere à frequência com que os docentes recorrem à utilização das diversas técnicas comportamentalistas, verificamos que estes privilegiam a utilização do Contrato de Contingências, seguindo-se o Custo da Resposta, o Programa de Economia de Fichas e o Time-Out, sendo de realçar a elevada percentagem de docentes $(36,4 \%)$ que nunca recorreu à aplicação desta última estratégia. Neste âmbito, não foram encontrados estudos que nos permitam estabelecer uma comparação com os resultados obtidos no nosso, fator este que evidencia novamente o caráter inovador da nossa investigação. Apenas no que se refere ao Time-Out apuramos que também Cardoso (2013) e Roberto (2013) comprovaram que esta é uma medida pouco frequente ao nível do $1{ }^{\circ}$ Ciclo do Ensino Básico.

Ao longo dos últimos anos temos assistido, no âmbito escolar, a um crescente aumento do número de crianças diagnosticadas com Perturbação de Hiperatividade e Défice de Atenção e a uma banalização e confusão desta perturbação com "falta de educaçáo". Neste sentido, torna-se imperativo continuar a realizar estudos focalizados no diagnóstico e, sobretudo, intervenção desta perturbação. Assim sendo, a realização desta investigação terá um contributo importantíssimo para os docentes do $1^{\circ} \mathrm{CEB}$, no sentido de lhes permitir compreender melhor esta perturbação, as diversas formas de intervenção e, sobretudo, estratégias e técnicas comportamentalistas a utilizar na intervenção em contexto escolar. Por outro lado, os docentes podem verificar quais as técnicas comportamentalistas que os seus colegas têm utilizado com maior frequência, para lidar com os comportamentos disruptivos que surgem frequentemente associados a esta perturbação, e qual a eficácia de cada uma delas. Neste âmbito, realçamos o caráter inovador da nossa investigação, na medida em que a mesma permitiu-nos constatar que em Portugal existem poucos ou quase nenhuns estudos que tenham centralizado as suas pesquisas nas técnicas comportamentalistas que os docentes utilizam em contexto de sala de aula. Neste sentido, a realizaçáo deste estudo deparou-se com algumas limitaçôes devido à falta de informação relativamente à utilização das técnicas comportamentalista pelos docentes do $1^{\circ} \mathrm{CEB}$, sobretudo no que se refere à eficácia e grau de frequência da sua utilização. 
Apesar das inúmeras investigaçôes que têm sido realizadas nas últimas décadas acerca da PHDA, esta continua a ser uma perturbação enigmática com consequências gravosas para o desenvolvimento das crianças, pelo que se torna impreterível continuar a apostar na divulgação desta problemática junto das escolas, sobretudo ao nível do $1^{\circ} \mathrm{CEB}$, na medida em que muitas vezes o seu diagnóstico surge no início da escolarização obrigatória.

\section{Referências}

ABAD-MAS, L. et al. Intervención psicopedagógica en el trastorno por déficit de atención/hiperactividad. Revista de Neurologia, v. 57, n. 1, p. 193-203, 2013.

ASSOCIAÇÃO AMERICANA DE PSIQUIATRIA (AAP). DSM-IV-TR: Manual de diagnóstico e estatística das perturbaçôes mentais. Lisboa: Climepsi Editores, 2002.

ARRUDA, M. Levados da breca: um guia sobre crianças e adolescentes com deficit de atenção e hiperactividade. Ribeirão Preto: Blanche Ricci Tabajara, 2008.

BOAVIDA, J.; CORDINHĀ, A. A criança hiperactiva: diagnóstico, avaliaçấo e intervenção. Revista Portuguesa de Clínica Geral, v. 24, p. 577-589, 2008.

CARDOSO, M. Percepçáo dos professores do $1^{\circ}$ ciclo do ensino básico face aos comportamentos perturbadores de crianças com Perturbaçáo de Hiperatividade com Défice de Atençáo. Lisboa, 2013. 125f. Dissertação (Mestrado em Educação) - Escola Superior de Educação João de Deus, Universidade Católica Portuguesa.

CHAVES, E. Procedimentos de Avaliaçáo e Intervençáo em Crianças com Défice de Atenção com Hiperatividade. Série Didática-Ciências Sociais e Humanas, 75, Vila Real. UTAD, 2008.

DUPAUL, G.; STONER, G. TDAH nas escolas. São Paulo: M.Books do Brasil Editora, 2007.

FERNANDES, E. Perturbaçáo de défice de atençáo e hiperactividade no âmbito escolar. Aveiro, 2007. 154f. Dissertação (mestrado em Desenvolvimento Psicológico). Universidade de Aveiro.

HORNER, R. et al. Elements of behavioral support plans: A technical brief. Exceptionality, v. 8, p. 205-215, 2000.

JÚLIO, A. Representaçóes acerca da Perturbaçáo de Hiperactividade e Défice de Atençáo. Coimbra, 2009. 134f. Dissertação (Mestrado em Psicologia) - Faculdade de Psicologia e Ciências da Educaçáo, Universidade de Coimbra.

LOPES, J. A Hiperatividade. Coimbra: Quarteto, 2004.

LORO-LÓPEZ, M. et al. Actualización en el tratamiento del trastorno por déficit de atención/hiperactividad. Revista de neurologia, v. 49, n. 5, p. 257-264, 2009.

LOURENÇO, M. Hiperatividade e Défice de Atençáo em contexto escolar. Estudo comparativo das perceçóes e atitudes de professores do $1 .^{\circ}, 2^{\circ}$ e $3 .^{\circ}$ Ciclos do Ensino Básico. Lisboa, 2009. 175f. Dissertaçáo (Mestrado em Educaçáo) - Faculdade de Motricidade Humana, Universidade Técnica de Lisboa.

MARAFÃO, A. Procedimentos de intervençáo comportamentalista em dois adolescentes com perturbaçáo de hiperatividade e défice de atençáo. Vila Real, 2012. 88f. Dissertaçáo (Mestrado em Educação) - Universidade de Trás-os-Montes e Alto Douro.

REIBER, C.; MCLAUGHLIN, T. Classroom interventions: methods to improve academic performance and classroom behavior for students with attention deficit/hiperactivity disorder. International Journal of Special Education, v. 19, n. 1, p. 1-13, 2004.

ROBERTO, T. Aprender para ajudar: PHDA. Lisboa, 2013. 73f. Dissertação (Mestrado em Educação) - Escola Superior de Educação João de Deus.

SANTOS, P. Hiperatividade e Défice de Atençáo em Contexto Escolar: Estudo Comparativo das Perceçóes e Impacto em Professores do Ensino Básico (Dissertação de Mestrado não publicada). Universidade Fernando Pessoa, Porto, Portugal, 2012.

SAUVÉ, C. Domesticar a hiperactividade e o défice de atençáo. Lisboa: Climepsi Editores, 2006.

SENA, S.; NETO, O. Distraído e a $\mathbf{1 0 0 0}$ por hora. Guia para familiares, educadores e portadores de Transtorno de Déficit de Atençáo/Hiperactividade. Porto Alegre: Artmed, 2007. 
SHELTON, T. L.; BARKLEY, R. A. Assessment and treatment of ADHD in children. In: ROBERTS, M. C. (Orgs.). Handbook of pediatric psychology. New York: Guilford, 1995.

SILVA, A. Mentes inquietas: TDAH: desatenção, hiperatividade e impulsividade. Rio de Janeiro: Objectiva, 2009.

SIMONSEN, B. et al. Evidenced-based practices in classroom management: Considerations for research to practice. Education and Treatment of Children, v. 31, p. 351-380, 2008.

ZAMBOM, L.; OLIVEIRA, M.; WAGNER, M. A técnica da economia de fichas no transtorno de déficit de atenção e hiperactividade. 2006. Disponível em: <http://www.psicologia.pt/artigos/textos/A0306.pdf>. Acesso em: 22 de janeiro de 2014.

\section{Correspondência}

Eduardo Chaves Cruz - Universidade de Trás-os-Montes e Alto Douro, Escola de Ciências Humanas e Sociais, Departamento de Educação e Psicologia, Edifício do CIFOP. Rua Dr. Manuel Cardona, Apartado 1013, Vila Real - 5001-558, Portugal.

E-mail: echaves@utad.pt - cecilia7159@gmail.com

Recebido em 02 de abril de 2015

Aprovado em 02 de julho de 2015 